\title{
THE QUANTITATIVE ESTIMATION OF SUDORIFEROUS ACTIVITY AND ITS RELATION TO TEMPERAMENT.
}

\author{
By L. C. F. CHEVENS and P. B. MUMFORD, \\ Parkside Mental Hospital, Macclesfield.
}

\section{INTRODUCTION.}

Temperament, as defined by McDougall ${ }^{1}$, is the sum of the effects on the mental life of the metabolic or chemical changes that are constantly going on in all the tissues of the body.

Temperaments have been roughly divided ${ }^{2}$ into four large groups: Sanguine, Choleric, Phlegmatic and Melancholic. In view of more recent work ${ }^{3}$ on the mutual balance of endocrine activity, it has been thought possible to correlate physical activities and characteristics with temperament. Clouston ${ }^{4}$ in 1904 remarked the doctrine of temperaments and diatheses. Kretschmer ${ }^{5}$ has attempted a selection of certain physical types as found amongst the mentally abnormal. The authors hereunder endeavour to adopt the above classification of temperament and, applying it to the 'sane' and 'insane,' seek for its correlation with one particular physical characteristic. The two former of these groups are stated by Stoddart ${ }^{6}$ to possess rapidity of thought and ease of receptivity, the two latter to possess a slower degree of thought and receptivity.

The observation of physical characteristics must to some extent at least be influenced by subjective criticism, and it is thought that observations made on a quantitative rather than a qualitative basis are free from this possible error. The correlation between mental type and physical states and reactions has been the subject of investigation at Parkside Mental Hospital for some time past. Some tentative conclusions have already been arrived at concerning a correlation between mental type on the one hand, and on the other $(a)$ blood sugar at rest ${ }^{7} ;(b)$ superficial vascular response ${ }^{8} ;(c)$ peripheral circulatory activity ${ }^{9}$; and $(d)$ the response to thermal stimulation ${ }^{10}$. Following on these, and particularly in view of the conclusions reached by the lastmentioned investigations, which showed a widely divergent sudoriferous response after external heat changes, an attempt is herewith made to place on an objective basis the correlation of mental type and temperament with one particular evidence of metabolic and chemical change, viz. loss of moisture from the skin. 
Popular belief has it that the possessor of a firm and warm handshake is a man of buoyant and energetic type, whereas the owner of a cold and clammy palm is of underactive and introspective tendencies. It is recognised clinically by writers on psychiatry that the primary dement has a moist and cyanosed hand, whereas the maniac has a hand which, though also moist, is of a raised temperature.

\section{TEGHNIQUE.}

In small part for these reasons, and in large part for more practical reasons, the hand up to the level of the wrist has been chosen for particular investigation regarding moisture-loss at rest. The apparatus employed and certain references to the quantity and activity of the sweat glands of the hand have already been described elsewhere ${ }^{11}$. In brief, a current of thoroughly dried air is drawn over the hand of an individual who has been kept at physical and mental rest for some period previous to the experiment, constant experimental conditions obtaining as far as possible. The air after passing over the skin of the hand is drawn through previously weighed tubes of sulphuric acid and the increase in weight is taken as indicating, at all events for comparative purposes, the sudoriferous loss from the hand examined, increases being measured in grammes per period of ten minutes.

\section{PERSONAL OBSERVATIONS.}

In order to obtain some estimate as to average moisture-loss amongst the mentally healthy a series of seven males and twenty-five females (nurses) was examined (Section A). Following on this (Section B) thirty cases of primary dementia were examined. An attempt was made (Section C) to find an equal number of cases of pure mania, but unfortunately only five have been found to date which could be controlled sufficiently to allow of the performance of the experiment with accuracy and with safety to patient and apparatus alike. The hand of the imbecile has been found to resemble the hand of the primary dement in respect of its clamminess, and for this reason (Section D) a series of twenty-three cases was examined. Finally, in view of the stated diminution of sweat secretion in melancholia, fifteen cases of this were also subjected to examination (Section E).

The exact figures obtained (grammes in 10 minutes) were as followsan average being taken in cases where two or more estimations were made :Section A. Normal healthy male adults. Age 20-40. 60, 35, 34, .28, $\cdot 25, \cdot 27, \cdot 36$. Average $\cdot 325$.

Normal healthy females of similar age. $\cdot 315, \cdot 180, \cdot 330, \cdot 400$, $.510, \cdot 425, \cdot 390, \cdot 495, \cdot 355, \cdot 160, \cdot 220, \cdot 150, \cdot 190, \cdot 265, \cdot 240, \cdot 280$, $.500, \cdot 280, \cdot 310, \cdot 265, \cdot 180, \cdot 145, \cdot 215, \cdot 130, \cdot 175$. Average $\cdot 29$.

Section B. Primary dements. Age 20-40. 15, .13, .12, .15, .07, .14, $\cdot 13, \cdot 10, \cdot 08, \cdot 14, \cdot 11, \cdot 07, \cdot 11, \cdot 26, \cdot 10, \cdot 22, \cdot 18, \cdot 17, \cdot 08, \cdot 10, \cdot 16$, $\cdot 09, \cdot 14, \cdot 11, \cdot 15, \cdot 10, \cdot 14, \cdot 18, \cdot 22, \cdot 18$. Average $\cdot 103$. 
Section C. Maniacs. Age 20-40. .24, .26, .87, .46, .19. Average 40 . Section D. Imbeciles. Age $20-40 . \cdot 35, \cdot 35, \cdot 15, \cdot 47, \cdot 18, \cdot 10, \cdot 23, \cdot 18$, $\cdot 18, \cdot 17, \cdot 27, \cdot 17, \cdot 17, \cdot 46, \cdot 19, \cdot 30, \cdot 61, \cdot 17, \cdot 40, \cdot 27, \cdot 17, \cdot 12, \cdot 18$. Average $\cdot 25$.

Section E. Melancholics. Age 20-40. -19, .135, .33, .112, .24, .18, 325, $\cdot 420, \cdot 176, \cdot 23, \cdot 24, \cdot 10, \cdot 27, \cdot 20, \cdot 36$. Average $\cdot 23$.

It is seen from the above figures that whereas in the dementia præcox group there is a consistently low figure in all cases, the other groups show a very wide variation indeed, and a search must be made for some factor other than one of gross mental disease before discussion as to the etiology of variations in sudoriferous activity is entered into.

In a single healthy adult many factors influence the amount of perspiration lost by the hand in a given period. The greater number of these are obvious and are well recognised : external temperature, relative atmospheric humidity, amount of clothing worn, and recent physical effort. These conditions were, however, kept nearly constant in the above examinations and exerted but little influence on the findings.

It was, however, early realised in the experiments that individuals of different temperament may be found included within the same mental type group. It was, therefore, decided to ask the Assistant Matron, from her personal and intimate knowledge, to classify the twenty-five nurses into those who were of quick mentality, emotional and restless, and those who were, by contrast, phlegmatic, steady and even dull; also to make a group of those who were intermediate in type. A similar but independent classification judged from capacity and quickness in duty was made by the A.M.O. in charge of the wards where these nurses were employed. A classification was made as follows :

Group A, where both judges placed the individuals amongst the emotional, restless or mentally quick type.

Group B, where both agreed as to 'average' type or where judges disagreed.

Group C, where both judges were of the opinion that individuals were phlegmatic and steady.

The results were as follows, taken from the readings of the females of Section A above :

Group A. $\cdot 315, \cdot 180, \cdot 330, \cdot 400, \cdot 510, \cdot 425, \cdot 500, \cdot 390,4 \cdot 95, \cdot 355, \cdot 160$. Average $\cdot 370$.

Group B. $\cdot 220, \cdot 250, \cdot 10, \cdot 265, \cdot 240, \cdot 280, \cdot 310, \cdot 280$. Average $\cdot 257$. Group C. $\cdot 265, \cdot 180, .145, \cdot 215, \cdot 130, \cdot 175$. Average $\cdot 185$.

This shows a very close correlation of temprament and sudoriferous activity, the mentally quick, emotional and restless group giving a figure exactly twice that of the steady ard phlegmatic group. An intermediate figure is given by the average group. It is to be noted that only two out of the 
eleven in Group A have a figure near that of the average of Group C, and that the latter has only one individual with a figure approaching even the average of Group B.

Encouraged by the above, we conducted an investigation on similar lines amongst the imbeciles. The A.M.O. in charge of the wards and the head attendant jointly classified the imbeciles into a loose grouping of 'restless' and 'apathetic.' Here again a close correspondence was noted ; the former group gave figures of $\cdot 35, \cdot 35, \cdot 47, \cdot 18, \cdot 23, \cdot 18, \cdot 18, \cdot 27, \cdot 19, \cdot 30, \cdot 61, \cdot 17, \cdot 40$, $\cdot 27, \cdot 18, \cdot 46$-average $\cdot 30$; and the apathetic group, $\cdot 15, \cdot 20, \cdot 10, \cdot 17, \cdot 17$, $\cdot 17, \cdot 12, \cdot 17$-average $\cdot 15$. In this series also the marked difference in reaction between the two temperamental types was in evidence.

When a subdivision of dementia præcox cases, in which the figure appears to be almost invariably low, was made the following results were obtained: Katatonics (15), average $\cdot 131$; hebephrenics (7), average $\cdot 136$; dementia paranoides (5), average $\cdot 14$; simple $(3)$, average $\cdot 120$.

It was not found possible to apply the above-mentioned classification of temperament to the melancholic group, though it was found that the cases which were noted at the time of examination to be markedly agitated gave figures of $\cdot 135, \cdot 33, \cdot 29, \cdot 420$ - average $\cdot 28$, which is slightly higher than the total average.

\section{DISGUSSION.}

Even from a casual examination of the above figures it is clear that there is a close correlation between temperament and sudoriferous activity. Assuming that temperament is the result of metabolic changes constantly occurring in the body, then the specious explanation of the findings is that an active physical and mental life, even though running in pathological channels, results in greater heat production. This necessitates a larger sudorific activity to retain the same temperature of the organism by evaporation. On the other hand, the secretion of sweat under constant experimental conditions may be looked on as an index of sympathetic activity. Developmentally the sympathetic is intimately related with the adrenals and thus with the endocrine system. Therefore, instead of regarding the increased secretion of moisture as a matter of cause and effect, one can think of its causation as correlated with an active endocrino-sympathetic system-the increased moisture-secretion and the active mental and physical life both being the results of a particular type of endocrine balance.

The imbecile group and the normal group are thus brought into line, while the findings in the melancholic group are by no means contradictory. In the primary dement we have almost invariably a reduced peripheral temperature with capillary and venous stasis. According to McWilliam ${ }^{12}$ such cases have an under-excitability of the sympathetic nervous system. Thus there is less evaporation of moisture from the hands and therefore a paradoxical increase of sweating. 
SUMMARY.

1. An attempt is made to correlate sweat loss with mental disease.

2. With the exception of primary dementia, and possibly mania, no such correlation is apparent.

3. A close correlation exists between temperament and sweat loss in the mentally healthy.

4. A close correlation exists between temperament and sweat loss in cases of imbeciles who have been roughly classified as 'restless' and 'apathetic.'

5. Primary dements show generally a decreased peripheral moisture loss.

6. The secretory activity of the sudoriferous glands of the hand is not decreased in melancholia.

7. The sudoriferous activity of the hands in mania appears to be increased.

8. The above changes may be explained on the basis of a need for heat dispersal as a direct consequerce of increased heat production, or they may be regarded as changes coexistent with temperamental variations in response to a primary alteration of metabolic activity.

Our kest thanks are due to Dr. H. Dove Cormac, Medical Superintendent. of Farkside Mental Hospital, for jermission to investigate and report on the above cases.

\section{REFERENGES.}

1 McDougall, Outline of Psychology, 1922.

2 Cole, Mental Diseases, 1919.

${ }^{3}$ Geikie Совв, The Organs of Internal Secretion, 1925, Chapter 12.

4 Clouston, Mental Diseases, 19099.

${ }^{5}$ Kretschmer, Physique and ('haraiter, 1925.

${ }^{6}$ Stoddart, Mind and its Disorders, 1919, 62.

' Parkin and MuMford, Jour. of Ment. Sci., July, 1923.

${ }^{8}$ Munford, M.D. Thesis, Victoria Cniversity, 1925.

9 MUMFord, Jour. of Ment. Sci., Jan., 1926.

10 Chevens and Mumford, Jour. of Ment. Sci., July, 1926.

11 Mumfiord, Jour. of Dermatol., June, 1927.

12 MoWilliam, Jour. of Mert. Sci., 1925, 781. 